\title{
Elopaino, kuntoluokka ja maidon pitoisuudet lehmän energiataseen kuvaajana
}

\author{
Päivi Mäntysaari ${ }^{1}$,Tuomo Kokkonen ${ }^{2}$, Martin Lidauer ${ }^{1}$, Esa Mäntysaari ${ }^{1}$ \\ ${ }^{1}$ Luonnonvarakeskus (Luke),Vihreä teknologia, 31600 Jokioinen, etunimi.sukunimi@luke.fi \\ ${ }^{2}$ Maataloustieteiden laitos, PL 28, 00014 Helsingin yliopisto, etunimi.sukunimi@helsinki.fi
}

\section{Tiivistelmä}

Lehmän energiataseen määrittäminen yksilötasolla on lypsykauden alussa tärkeää paitsi managementin niin myös jalostuksen kannalta. Lehmän energiatasetta voidaan arvioida laskemalla lehmälle laskennallinen energiatase ( $\mathrm{EB}_{\text {in-out }}$ ) lehmän energian syönnin ja energian kulutuksen perusteella. Vaihtoehtoisesti energiatasetta voidaan arvioida indikaattoreiden kuten elopainon (EP), kuntoluokan $(\mathrm{KL})$ ja näiden muutosten $(\Delta \mathrm{EP} ; \Delta \mathrm{KL})$ sekä maidon rasva-valkuaissuhteen (FP) perusteella. Indikaattoreihin perustuneiden $\mathrm{EB}_{\text {in-out }}$ ennusteiden tarkkuus on jäänyt kuitenkin yleensä alhaisiksi. Syy alhaiseen ennustevarmuuteen voi olla itse $\mathrm{EB}_{\text {in-out }}$ arviossa, sillä laskelmissa käytetään kaikille lehmille samoja keskimääräisiä energiatarpeita. Tässä selvityksessä käytettiin plasman vapaiden rasvahappojen (NEFA) pitoisuutta biomarkkerina lehmän energian mobilisoinnille ja energiataseelle sekä kartoitettiin plasman NEFA-pitoisuuden ja energiataseindikaattoreiden välisiä yhteyksiä. Data käsitti 10032 EP-, syönti- ja maito-, 279 KL- ja 261 NEFA-mittausta 56 Ayrshire ensikolta. Verinäytteet NEFA-analyyseihin otettiin kahdesti laktaatioviikoilla 2 ja 3 ja kerran viikolla 20. Maitonäytteet kerättiin samoina päivinä sekä lisäksi tuotosseurantapäivinä. Päivittäisen satunnaisvaihtelun poistamiseksi EP-mittaukset tasoitettiin käyttäen satunnaisregressiomallia, jossa oli sekä kiinteä että lehmäkohtainen laktaatiopäivän vaikutus. Plasman NEFA-pitoisuuden laktaatioviikolla 20 katsottiin olevan eläimen perustaso ja poikkeamaa perustasosta (dNEFA) käytettiin laskelmissa. Aineiston lehmillä EKM (kg/d), maidon rasva ja valkuainen (\%), EP (kg) ja KL (asteikko 1-5) olivat keskimäärin ( \pm sd) 30,3 $( \pm 4,60), 4,43( \pm 0,51), 3,59( \pm 0,32), 574( \pm 53)$, and 3,19 $( \pm 0,38)$. NEFA-pitoisuus laktaatioviikolla kaksi oli keskimäärin $( \pm \mathrm{sd}) 0,704( \pm 0,363)$, viikolla kolme $0,526( \pm 0,275)$ ja laktaatioviikolla $200,123( \pm 0,035) \mathrm{mmol} / \mathrm{l}$. Tutkituista energiataseindikaattoreista voimakkaimmin dNEFA-pitoisuuden kanssa korreloivat $\triangle \mathrm{EP}(-0,57)$ ja maidon FP $(0,53)$. Korrelaatio dNEFAn sekä $\Delta$ KL välillä oli $-0,20$. Kehitimme tilastollisen monitekijäisen mallin dNEFAn ennustamiseen. Paras ennuste saatiin yhtälöllä, joka sisälsi $\Delta \mathrm{EP}, \mathrm{FP}, \mathrm{KL}, \Delta \mathrm{KL}$ ja KL $* \Delta \mathrm{KL}$ sekä laktaatiopäivien määrän. Korrelaatio ennustetun ja mitatun dNEFAn välillä oli 0,77 , mikä oli korkeampi kuin dNEFAn ja $\mathrm{EB}_{\text {in-out }}$ välinen korrelaatio $(0,69)$. Tämä viittaa siihen, että indikaattoreihin perustuva ennuste kuvasi paremmin lehmän todellista energiatasetta kuin laskennallinen energiatase $\mathrm{EB}_{\text {in-out }}$.

Asiasanat: Lypsylehmä, energiatase 


\section{Johdanto}

Lypsykauden alussa lehmien rehun syönti ei useinkaan pysty kattamaan energian tarvetta, joten lehmä joutuu käyttämään kudosvarastojaan lisäenergialähteenä. Tästä johtuen ovat lehmät lypsykauden alussa lähes poikkeuksetta negatiivisessa energiataseessa. Vaikka lyhytkestoisena negatiivinen energiatase on nykypäivän korkeatuottoisille lehmille hyväksyttävää, niin pitkään kestävä ja runsas kudosvarastojen mobilisointi ei ole suotavaa, sillä se usein johtaa lisääntyneeseen sairastavuuteen ja heikentyneeseen hedelmällisyyteen (de Vries ym. 1999, Collard ym. 2000). Lehmän energiataseen määrittäminen yksilötasolla on lypsykauden alussa tärkeää paitsi managementin niin myös jalostuksen kannalta. Lisäämällä lypsykaudenalun energiatase jalostuksen kohteeksi voitaisiin lehmien osalta huomioida myös odotettavissa olevan metabolisen stressin riski.

Lehmän energiatasetta voidaan arvioida laskemalla lehmälle laskennallinen energiatase $\left(\mathrm{EB}_{\text {in- }}\right.$ out) lehmän energian syönnin ja energian kulutuksen perusteella. Tämä edellyttää rehun syönnin mittaamista, mikä tilatasolla on nykyisin menetelmin hankalaa. Vaihtoehtoisesti energiatasetta voidaan arvioida helpommin määritettävien indikaattoreiden, kuten elopainon (EP), kuntoluokan (KL) ja maidon rasva-valkuaissuhteen (FP) perusteella. Mikäli elopainonmuutos ( $\triangle \mathrm{EP}$ ) ja sen koostumus voitaisiin mitata harhattomasti, kuvaisi $\Delta \mathrm{EP}$ suoraan lehmän energiatasetta. Myös maidon pitoisuudet ja niiden suhteet heijastavat lehmän energiatasetta (Heuer ym. 2000,). Negatiivisessa energiataseessa kudoksista mobilisoidaan runsaasti rasvahappoja maitorasvan synteesiin, mutta vain rajoitetusti aminohappoja maitovalkuaisen synteesiin, joten rasvapitoisuus suhteessa valkuaispitoisuuteen nousee. Eri indikaattoreihin perustuvaa energiatase-ennustemalleja on esitetty useissa tutkimuksissa (Heuer ym. 2000, Reist ym. 2002, Friggens ym. 2007, Mäntysaari ja Mäntysaari 2010). Indikaattoreihin perustuneiden ennusteiden tarkkuus on kuitenkin jäänyt yleensä alhaisiksi, ennustevarmuuden vaihdellessa $0.2-0.4$. Ennustettavaa energiatasetta on tutkimuksissa yleensä kuvattu laskennallisella energiataseella. Syy alhaiseen ennustevarmuuteen voi olla itse $\mathrm{EB}_{\text {in-out }}$ arviossa, sillä $\mathrm{EB}_{\text {in-out }}$ laskelmissa vähennetään lehmän energian syönnistä tarvenormien mukaan laskettu energian kulutus, jolloin kaikille lehmille käytetään samoja keskimääräisiä energiatarpeita. Kuitenkin tutkimuksissa on todettu, että yksilöiden välillä on eroja rehun hyväksikäytössä ja näin ollen myös tarpeissa (Mäntysaari ym. 2012).

Lehmän mobilisoidessa kudosrasvoja plasman vapaiden rasvahappojen (NEFA) pitoisuus nousee, joten NEFA-pitoisuutta voidaan pitää lehmän energiataseen biomarkkerina. Tässä tutkimuksessa selvitettiin energiataseindikaattoreiden kykyä kuvata plasman NEFA-pitoisuutta. Hypoteesina oli, että energiataseindikaattoreihin perustuvan ennusteen yhteys plasman NEFApitoisuuteen on voimakkaampi kuin laskennallisen energiataseeseen.

\section{Aineisto ja menetelmät}

Tutkimuksen aineisto kerättiin osana meneillään olevaa pohjoismaista 'Nordic Feed Efficiency' projektia. Laskelmissa käytettyyn aineistoon sisällytettiin Luken Jokioisten karjassa vuosina 2013 2014 kerätyn 56 Ayrshire-ensikon tiedot. Lehmiltä mitattiin syönti-, tuotos ja elopainotiedot päivittäin laktaatiopäivinä 3 - 280. Lehmien KL arvioitiin asteikolla 1-5 (Edmonson ym. 1989) neljän viikon välein. Verinäytteet NEFA-analyyseihin otettiin kahdesti laktaatioviikoilla 2 ja 3 ja kerran viikolla 20. Plasman NEFA-pitoisuus analysoitiin Helsingin yliopistolla Viikin laboratoriossa (NEFA-kit, Walco Chemicals). Maitonäytteet maidon pitoisuusmäärityksiin kerättiin samoina päivinä kuin verinäytteet sekä lisäksi tuotosseurantapäivinä. Kaiken kaikkiaan data käsitti 10032 EP-, syönti- ja maito-, 279 KL- ja 261 NEFA-mittausta. 
Kaikilla lehmillä oli yhtenäinen ruokinta. Lehmät saivat säilörehua vapaasti. Lehmän väkirehuannos määräytyi säilörehun D-arvon ja lypsykauden vaiheen perusteella. D-arvon ollessa 680 $-700 \mathrm{~g} / \mathrm{kg} \mathrm{ka}$ oli rehuannoksen väkirehupitoisuus kuiva-aineessa $520 \mathrm{~g} / \mathrm{kg}$ laktaatiopäivinä 1-150, minkä jälkeen väkirehupitoisuus putosi $450 \mathrm{~g} / \mathrm{kg}$ ka. Kuitenkin mikäli säilörehun D-arvo lisääntyi tai laski edellä annetuista arvoista väkirehun pitoisuus seosrehussa lisääntyi tai laski $20 \mathrm{~g} / \mathrm{kg} \mathrm{ka} \mathrm{jokaista}$ $10 \mathrm{~g} / \mathrm{kg}$ ka D-arvon nousua tai laskua kohti. Keskimäärin aineiston lehmillä oli rehuannoksen kuivaaineesta 49,5 \% väkirehua. Säilörehusta otettiin rehunäytteet kaksi kertaa ja väkirehusta kerran viikossa. Rehuanalyysit tehtiin Luken laboratoriossa standardimenetelmin. Säilörehun orgaanisen aineen sulavuus määritettiin orgaanisen aineen in vitro pepsiini-sellulaasiliukoisuuden perusteella (Nousiainen ym. 2003) käyttäen in vivo-sulavuuskokeisiin perustuvia muuntoyhtälöitä (Huhtanen ym. 2006). Rehujen rehuarvot laskettiin Rehutaulukoissa (Luke, 2015) esitettyjen laskentaperusteiden mukaan.

Lehmille laskettiin päivittäinen kuiva-aineen syönti, energian saanti ja energiakorjattu maitotuotos. Lehmät punnittiin sekä aamu- että iltalypsyn jälkeen, eli jokaiselle päivälle saatiin lehmälle kaksi punnitusta, joista laskettiin keskiarvo. Elopainon päivittäisen satunnaisvaihtelun poistamiseksi keskimääräiset päivittäiset EP-mittaukset tasoitettiin käyttäen satunnaisregressiomallia, jossa oli sekä kiinteä että lehmäkohtainen laktaatiopäivän vaikutus (Mäntysaari \& Mäntysaari, 2015). Päivittäinen KL määritettiin arvioitujen KL-havaintojen perusteella olettaen muutoksen olevan lineaarisen määritysten välillä. Energiakorjattu maitotuotos (EKM) laskettiin tuotoksen ja pitoisuuksien perusteella (Sjaunja ym. 1991). $\mathrm{EB}_{\text {in-out }}$ laskettiin syödyn energian ja ylläpitoon ja maidontuotantoon käytetyn energian erotuksena. Ylläpitoon ja maidontuotantoon käytetty energia laskettiin Rehutaulukoissa (Luke, 2015) annetuiden tarvenormien mukaan.

Plasman NEFA-pitoisuuden laktaatioviikolla 20 katsottiin olevan eläimen perustaso ja poikkeamaa perustasosta (dNEFA) käytettiin laskelmissa. dNEFAn ja energiatase indikaattorimuuttujien välisiä yhteyksiä tarkasteltiin korrelaation ja regression avulla ( $S A S^{\circledR}$ Mixed). Regressioyhtälön tavoitteena oli kuvata lehmäkohtaista plasman NEFA-pitoisuutta (dNEFA) lypsykauden alussa viikoilla 2 ja 3. Selittävinä muuttujina käytettiin EP, KL ja niiden muutosta sekä maidon FP. Indikaattorimuuttujiin perustuvien mallien käyttökelpoisuutta lehmän todellisen energiataseen mittarina arvioitiin Akaike informaatiokriteerin (AIC) ja jäännösvirheen avulla sekä dNEFAn ja ennustetun NEFAn välisellä korrelaatiolla.

\section{Tulokset ja tulosten tarkastelu}

Koeaineiston lehmien keskimääräiset maitotuotos- ja pitoisuus- sekä syöntitiedot on annettu taulukossa 1. Aineiston lehmien keskimääräinen EKM-tuotos oli $30,3 \mathrm{~kg} / \mathrm{pv}$ ja maidon rasva- ja valkuaispitoisuus 4,43 ja 3,59\%. Lehmät söivät keskimäärin $20,3 \mathrm{~kg} \mathrm{ka} / \mathrm{pv}$, mikä vastasi $218 \mathrm{ME}$ MJ/pv. Lehmät painoivat keskimäärin $574 \mathrm{~kg}( \pm 53)$ ja keskimääräinen kuntoluokka oli 3,19 $( \pm 0,38)$. Plasman NEFA-pitoisuus määritettiin kahdesti laktaatioviikolla 2 ja 3 ja kerran laktaatioviikolla 20. Keskimäärin NEFA-pitoisuus laktaatioviikolla kaksi oli $( \pm$ sd) $0,704( \pm 0,363)$, viikolla kolme 0,526 $( \pm 0,275)$ ja viikolla $200,123( \pm 0,035) \mathrm{mmol} / \mathrm{l}$. NEFA-pitoisuudet viikkojen 2,3 ja 20 määrityspäivinä ja vastaavien päivien $\triangle \mathrm{EP}$ on esitetty kuvassa 1 . Tulokset osoittavat, että näyteviikoksi valitut laktaatioviikot 2 ja 3 osuivat hyvin lehmien voimakkaan kudosvarastojen mobilisoinnin vaiheeseen ja viikko 20 jo positiivisen energiataseen vaiheeseen. Tämä voidaan todeta myös kuvassa 2 esitetyistä maidon FP ja $\Delta \mathrm{KL}$ muutoksista laktaation aikana. 
Taulukko 1. Lehmien keskimääräiset tuotos-, syönti-, elopaino- ja energiatasetiedot.

\begin{tabular}{|l|l|l|}
\hline & Keskiarvo & Hajonta \\
\hline EKM, kg/d & & \\
Maidon rasva, g/kg & 30,3 & 4,60 \\
Maidon valkuainen, g/kg & 44,3 & 5,1 \\
\hline Kuiva-aine syönti, kg/pv & 35,9 & 3,2 \\
ME-syönti, MJ/pv & 20,3 & 3,20 \\
\hline Elopaino, kg & 218 & 31,7 \\
Kuntoluokka & 574 & 53 \\
\hline EB Bin-out, ME MJ/pv & 3,19 & 0,38 \\
$\quad$ Laktaatioviikolla 2 & & \\
Laktaatioviikolla 3 & $-40,2$ & 25,7 \\
Laktaatioviikolla 20 & $-28,3$ & 26,1 \\
\hline
\end{tabular}

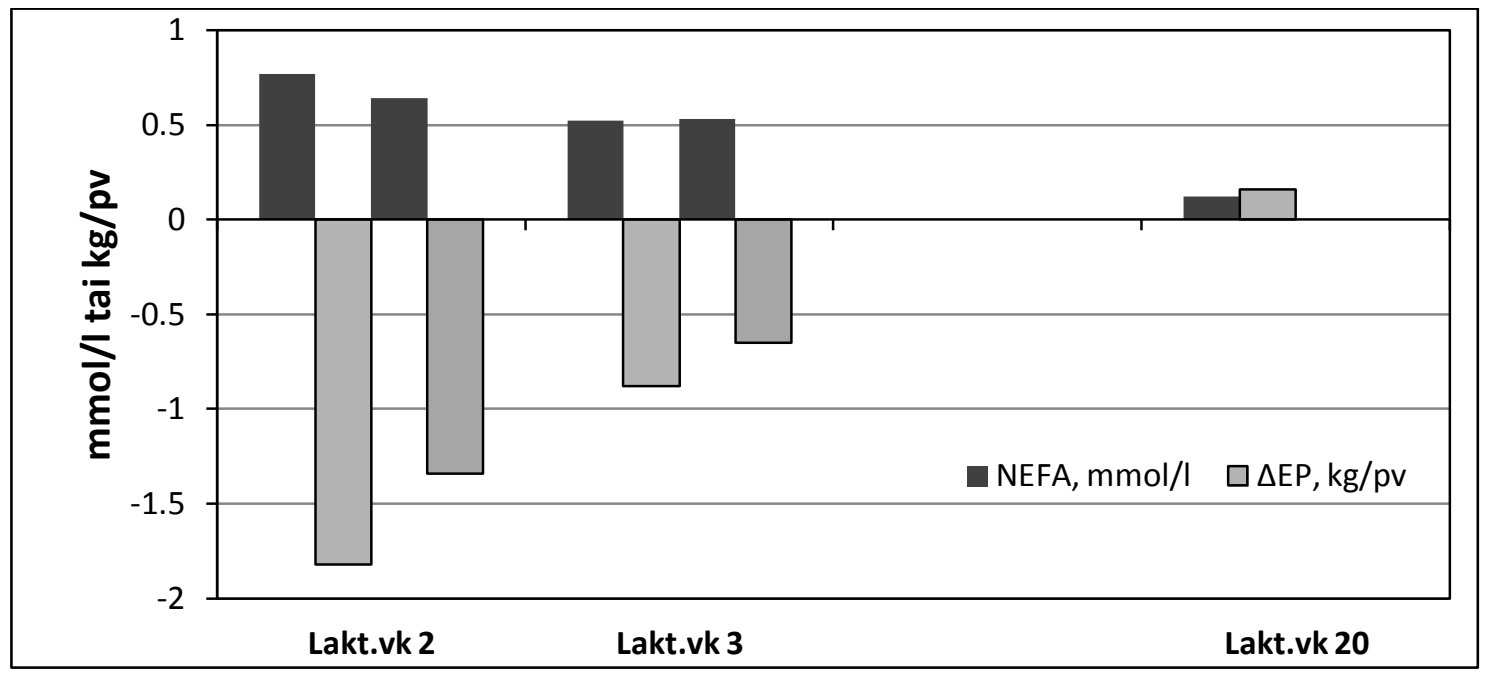

Kuva 1. Lehmien plasman NEFA-pitoisuus (mmol/l) ja elopainon muutos $(\Delta \mathrm{EP}, \mathrm{kg} / \mathrm{d})$ laktaatioviikoilla 2,3 ja 20 . 


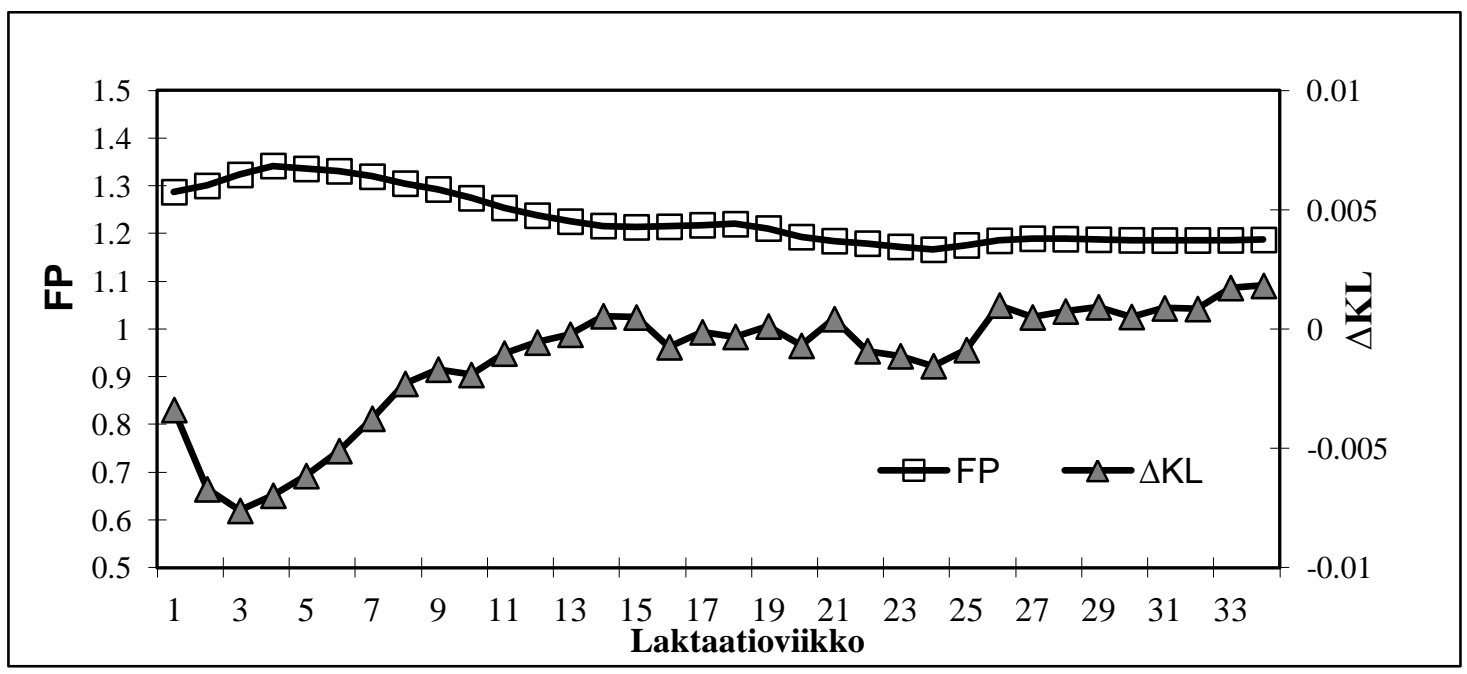

Kuva 2. Lehmien maidon rasva-valkuaissuhde (FP) ja kuntoluokan muutos ( $\Delta \mathrm{KL}$ ) laktaation aikana

Taulukko 2. Lypsykauden alun plasman NEFA-pitoisuutta kuvaavien regressioyhtälöiden luotettavuus ja ennustetun NEFA- ja mitatun NEFA-pitoisuuden välinen korrelaatio.

\begin{tabular}{|c|c|c|c|}
\hline Malli $^{1}$ & AIC & jäännösvirhe & $\begin{array}{l}\text { Korrelaatio } \\
\text { NEFA }_{\text {ennuste, }} \text { NEFA }\end{array}$ \\
\hline$\Delta \mathrm{EP}$ & 65,3 & 0,0795 & 0,57 \\
\hline FP & 74,4 & 0,0875 & 0,53 \\
\hline$\Delta \mathrm{KL}$ & 122,9 & 0,1193 & 0,20 \\
\hline$\Delta \mathrm{KL}+\mathrm{KL}+\mathrm{KL}^{*} \Delta \mathrm{KL}$ & 101,6 & 0,1097 & 0,31 \\
\hline$\Delta \mathrm{EP}+\mathrm{FP}$ & 26,1 & 0,0637 & 0,63 \\
\hline$\Delta \mathrm{EP}+\mathrm{FP}+\Delta \mathrm{KL}$ & 17,9 & 0,0617 & 0,69 \\
\hline$\Delta \mathrm{EP}+\Delta \mathrm{KL}+\mathrm{KL}+\mathrm{KL} * \Delta \mathrm{KL}$ & 42,3 & 0,0718 & 0,62 \\
\hline$\Delta \mathrm{EP}+\mathrm{FP}++\Delta \mathrm{KL}+\mathrm{KL}+\mathrm{KL} * \Delta \mathrm{KL}$ & 2,9 & 0,0573 & 0,73 \\
\hline$\Delta \mathrm{EP}+\mathrm{FP}++\Delta \mathrm{KL}+\mathrm{KL}+\mathrm{KL} * \Delta \mathrm{KL}+\operatorname{dim}$ & -10.7 & 0,0488 & 0,77 \\
\hline
\end{tabular}

Selittävät muuttujat: $\mathrm{FP}=$ maidon rasva-valkuais-suhde; $\mathrm{KL}=$ kuntoluokka; $\Delta \mathrm{KL}=$ kuntoluokan muutos; $\triangle \mathrm{EP}=$ elopainon muutos; $\operatorname{dim}=$ päivää poikimisesta.

$\mathrm{NEFA}_{\text {ennuste }}=$ malliin perustuva NEFA ennuste. $\mathrm{AIC}=$ Akaike informaatiokriteeri, mitä pienempi sitä sopivampi malli.

Tutkituista energiataseindikaattoreista voimakkaimmin dNEFA-pitoisuuden kanssa korreloivat $\triangle$ EP (korrelaatio -0,57) ja maidon FP $(0,53)$. Korrelaatio dNEFAn sekä $\Delta$ KL välillä oli $-0,20$. Testasimme eri indikaattorimuuttujiin perustuvia tilastollisia monitekijämalleja dNEFAn ennustamiseen lypsykauden alussa (Taulukko 2). Yksittäisistä tekijöitä $\Delta \mathrm{EP}$ ennusti parhaiten ja FP toiseksi parhaiten plasman dNEFA-pitoisuutta arvioitaessa AIC ja jäännösvirheen perusteella. Toisin kuin tässä tutkimuksessa, aikaisemmissa tutkimuksissa FP ennusti energiatasetta selvästi $\Delta \mathrm{EP}$ luotettavammin (Mäntysaari \& Mäntysaari, 2010). $\triangle$ KL ennusti selvästi heikommin dNEFA kuin $\triangle \mathrm{EP}$ ja FP. Kuntoluokkaan perustuva ennuste kuitenkin varmentui, kun malliin lisättiin $\Delta \mathrm{KL}$ :sen lisäksi KL ja sen yhdysvaikutus $\Delta \mathrm{KL}$ :aan. Paras ennuste saatiin yhtäld̈li, joka sisälsi $\Delta \mathrm{EP}, \mathrm{FP}, \mathrm{KL}$, $\Delta K L$ ja KL ${ }^{*} \Delta K L$ sekä laktaatiopäivien määrän (Taulukko 2 ja 3). Korrelaatio parhaan ennusteen ja mitatun dNEFAn välillä oli 0,77, mikä oli korkeampi kuin dNEFAn ja $E_{\text {in-out }}$ välinen korrelaatio

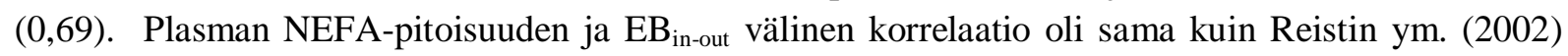
tutkimuksessa. He laskivat korrelaatioksi 0,685 laktaatioviikoilla 1-10. Korkeampi korrelaatio 
dNEFAn ja ennustetun energiataseen kuin $\mathrm{EB}_{\text {in-out }}$ välillä viittaa siihen, että indikaattoreihin perustuva ennuste kuvasi paremmin lehmän todellista energiatasetta kuin laskennallinen energiatase $\mathrm{EB}_{\text {in-out. }}$

Taulukko 3. Parhaiten lypsykauden alun NEFA-pitoisuutta kuvaavan regressioyhtälön ratkaisut ja niiden selittämä osuus vaihtelusta.

\begin{tabular}{|l|l|l|l|l|}
\hline Regressiotekijä & Regressiokerroin & SE & P & $\begin{array}{l}\text { Kumulatiivinen } \\
\text { selitysaste-\% }\end{array}$ \\
\hline Leikkauspiste & $-0,1314$ & 0,2358 & 0,581 & \\
$\Delta \mathrm{EP}$ & $-0,1079$ & 0,0166 & $<0,0001$ & 32,9 \\
$\mathrm{FP}$ & 0,6470 & 0,1103 & $<0,0001$ & 39,3 \\
$\Delta \mathrm{KL}$ & 20,8510 & 7,1537 & 0,0664 & 48,4 \\
$\mathrm{KL}$ & $-0,0987$ & 0,0533 & 0,0041 & 48,4 \\
KL* $\Delta \mathrm{KL}$ & $-7,4485$ & 2,2661 & 0,0013 & 52,6 \\
$\operatorname{dim}$ & $-0,00212$ & 0,0004 & $<0,0001$ & 59,7 \\
& & & & \\
\hline
\end{tabular}

\section{Johtopäätökset}

Käyttäen plasman NEFA-pitoisuutta lehmän energiataseen biomarkkerina todettiin, että elopainon ja kuntoluokan muutoksen ja maidon rasva-valkuaispitoisuuden perusteella voidaan hyvin ennustaa lehmän alkulypsykauden energiatasetta. Indikaattoreihin perustuva ennuste kuvasi paremmin lehmän todellista energiatasetta (dNEFA) kuin laskennallinen energiatase $\mathrm{EB}_{\text {in-out. }}$ Onkin todennäköistä, että $\mathrm{EB}_{\text {in-out }}$ laskelmissa käytetyt tarvenormit eivät päde nykylehmille ja lisäksi lehmien väliset erot rehun hyväksikäytössä aiheuttavat virhettä laskelmiin.

\section{Kirjallisuus}

Collard, B. L., Boettcher, P.J., Dekkers, J.C.M., Petitclerc, D. \& Schaeffer, L.R. 2000. Relationshipsbetween energy balance and health traits of dairy cattle in early lactation. J. Dairy Sci. 83:2683-2690.

de Vries, M. J., van der Beek, S., Kaal-Lansbergen, L.M.T.E., Ouweltjes, W. \& Wilmink, J.B. 1999.Modeling of energy balance in early lactation and the effect of energy deficits in early lactation on first detected estrus postpartum in dairy cows. J. Dairy Sci. 82:1927-1934.

Edmonson, A.J., Lean, I.J., Weaver, L.D., Farver, T. \& Webster, G. 1989. A body condition scoringchart for Holstein dairy cows. J. Dairy Sci. 72:68-78.

Friggens, N. C., Ridder,C. \& Løvendahl, P. 2007. On the use of milk composition measures to predict the energy balance of dairy cows. J. Dairy Sci. 90:5453-5467.

Heuer, C., Van Straalen, W.M., Schukken, Y.H., Dirkzwager, A. \& Noordhuizen, J.P.T.M. 2000. Prediction of energy balance in a high yielding dairy herd in early lactation: model development and precision. Livest. Prod. Sci. 65:91-105.

Huhtanen, P., J. Nousiainen, and M. Rinne. 2006. Recent developments in forage evaluation with special reference to practical applications. Agric. and Food Sci. 15:293-323.

Luke. 2015. Feed tables and nutrient requirements.[online]. Jokioinen. Luke Luonnonvarakeskus. [cited 1.6.2015]. Available at: http://www.luke.fi/feedtables.

Mäntysaari, P. \& Mäntysaari, E.A. 2010. Predicting early lactation energy balance in primiparous Red Dairy Cattle using milk and body traits. Acta Agric. Scand., Section A - Anim. Sci. 60:79-87.

Mäntysaari, P., Liinamo, A.-E. \& Mäntysaari E.A. 2012. Energy efficiency and its relationship with milk, body and intake traits and energy status among primiparous Nordic Red dairy cattle. J. Dairy Sci. 95:3200-3211.

Mäntysaari, P. \& Mäntysaari, E.A. 2015. Modeling of daily body weights and body weight changes of Nordic Red cows. J. Dairy Sci. 98:6992-7002. 
Nousiainen, J., Rinne, M., Hellämäki, M, \& Huhtanen, P. 2003. Prediction of the digestibility of the primary growth of grass silages harvested at different stages of maturity from chemical composition and pepsin-cellulase solubility, Anim. Feed Sci. and Technol. 103: 97-111.

Reist, M., Erdin, D., von Euw, D., Tschuemperlin, K., Leuenberger, H., Chilliard, Y., Hammon, H. M., Morel, C., Philipona, C., Zbinden, Y., Kuenzi, N. \& Blum, J. W. 2002. Estimation of energy balance at the individual and herd level using blood and milk traits in high-yielding dairy cows. J. Dairy Sci. 85, 3314-3327. 